\title{
Revealing the Hierarchical Microstructure of Innovative Additively Manufactured Metal Parts with Conventional Light Microscopy
}

\author{
Lavinia Tonelli ${ }^{1}$ (D)
}

Received: 27 October 2020 / Revised: 23 December 2020 / Accepted: 24 February 2021 / Published online: 29 March 2021

(c) The Author(s) 2021

\begin{abstract}
Additively manufactured parts are characterized by a peculiar microstructure, originated by the distinctive layer-by-layer process. In case of additive technology based on the localized melting of a metallic feedstock, as laser-based powder bed fusion (LPBF), the resulting microstructure has a hierarchical arrangement, consisting of macro- and microscopical features affecting the final properties. Commonly, several advanced metallographic techniques are adopted in order to reveal the LPBF microstructure. However, main microstructural features can be also qualitatively appreciated by means of conventional light microscopy. The present work aims at describing how the peculiar LPBF microstructure of the Co28Cr6Mo alloy can be characterized, along with its main microstructural features, by means of the sole light microscopy.
\end{abstract}

Keywords Additive manufacturing $\cdot$ Powder bed fusion $\cdot$ Selective laser melting $\cdot$ Co alloys

\section{Introduction}

In the most recent years, metal additive manufacturing technologies, and especially the laser-based powder bed fusion (LPBF) one, have benefited from high interest of both research and industrial fields [1,2]. LPBF relies on the localized melting of subsequent layers of fine metallic powder by means of a laser beam and owes its success mainly in the possibility of realizing component with a high degree of geometrical complexity. Such complexity is facilitated by the layer-wise solution that allows overcoming most of the technological restrains of the so-called conventional manufacturing routes. However, it should be mentioned that from the material point of view, LPBF results also in a distinctive, extremely fine and metastable microstructure that guarantees good mechanical properties even in the as-built condition [3]. The origin of such distinctive microstructure lies in the peculiar solidification conditions that the processed alloy experiences [4]. For each subsequent layer, the metal, initially in the form of spherical powder, is selectively melted by the laser beam forming the so-called melt pool. Due to the high cooling

Lavinia Tonelli

lavinia.tonelli2@unibo.it

1 Department of Industrial Engineering, University of Bologna, Viale del Risorgimento 4, 40136 Bologna, Italy rate, approx. $10^{6} \mathrm{~K} / \mathrm{s}$, the metal rapidly solidifies following the direction of the maximum thermal gradient (e.g. the building direction). As a consequence, molten metal solidifies on a solid substrate made of its same chemical composition (i.e. the previously processed layer), leading to an epitaxial grain growth [5]. Additionally, because of the high cooling rate, the final microstructure is extremely fine and the solubility of alloy elements is generally extended, inducing a supersaturated metastable solid solution [6]. In summary, LPBF microstructure is characterized by the following peculiar microstructural features: (i) a layered structure formed by subsequent solidified melt pools, (ii) epitaxial grains crossing-over layers, (iii) very fine substructure formed within grains. These features, appreciable from low to high magnifications, make the LPBF microstructure hierarchical. Solidified melt pools are usually observed by conventional light microscopy, while the other microstructural features usually need advanced metallographic techniques. In case of the Co28Cr6Mo LPBF alloy here investigated, for example, epitaxial grain growth was examined with electron backscattered diffraction (EBSD) $[7,8]$ and scanning electron microscopy (SEM) [9]. The fine substructure, characterized by a cellular morphology for this alloy, is commonly resolved by SEM [9-12]. The present work aims at showing how, with the only adoption of conventional light microscopy, the above-mentioned LPBF microstructural features can be 
observed. Furthermore, by adopting a sole instrument it is also possible to investigate possible interactions among the features, being the main advantage of this method. In the present work, the method was applied to a Co28Cr6Mo alloy for biomedical application, but it was also successfully adopted in case of others metal alloys processed by additive manufacturing, such as the AISI 304L austenitic stainless steel [13].

\section{Experimental}

Small blocks $\left(20 \times 6 \times 30 \mathrm{~mm}^{3}\right)$ were produced starting from gas-atomized Co28Cr6Mo powder (LPW Technology Ltd, Runcorn, UK) using a LPBF machine equipped with a continuous wave laser source (SISMA MYSINT100). Process parameters were chosen in order to obtain highdensity optimized samples, as described in previous works [14, 15]. A rotating chessboard scanning pattern was employed and samples were built along the direction perpendicular to the building platform (i.e. vertical direction). As no post-process heat treatments were applied to the samples, the microstructure was characterized in the as-built condition.

Microstructural analyses were carried out on both vertical (V, i.e. parallel to the building direction), and horizontal (H, i.e. parallel to the building platform) sections, as described in Fig. 1. The analysis of both $\mathrm{V}$ and $\mathrm{H}$ sections, in fact, allows the investigation of the microstructural anisotropy typical of additive process as LPBF.

Metallographic sections were embedded in a phenolic resin and subjected to the following metallographic preparation, as described in [16]:

- Grinding with SiC papers: $180,320,600,800$ and 1200 grit.

- Polishing with polycrystalline diamond suspensions (9, 3 and $1 \mu \mathrm{m}$ ) up to a mirror finish.

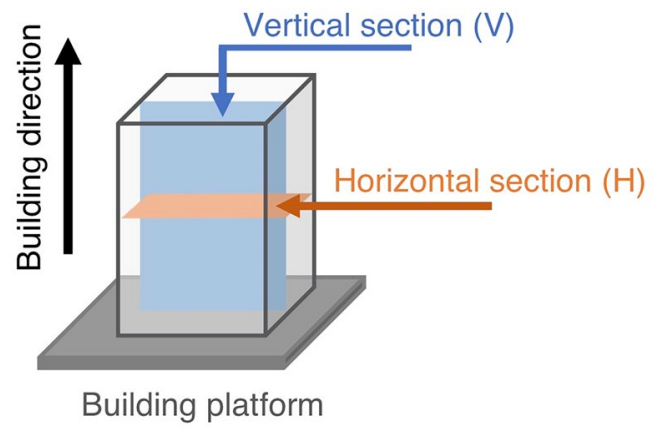

Fig. 1 Schematic representation of metallographic sections extraction
- Electrochemical etching performed at $4 \mathrm{~V}$ for $20 \mathrm{~s}$ in a 5 $\mathrm{mL} \mathrm{HCl}, 10 \mathrm{~g} \mathrm{FeCl}_{3}$ and $100 \mathrm{~mL} \mathrm{H}_{2} \mathrm{O}$ solution.

Conventional light microscopy (LM) was chosen to investigate the distinctive microstructure of the LPBF alloy. A Zeiss Imager A1 optical microscope was adopted, operating at low $(5 \times)$ and high $(50 \times)$ magnification with a $0.5 \times$ camera adapter. Polarized light, bright and dark fields were exploited to reveal the microstructural features peculiar of LPBF.

\section{Results and Discussion}

The expected microstructure resulting from LPBF process is schematically represented in Fig. 2. Three main microstructural features can be identified: (i) borders of the solidified melt pools, (ii) epitaxial grains and (iii) fine cellular substructure formed within grains. As depicted by the scheme in Fig. 2, the above-mentioned features change their morphology according to the observed sections. In fact, as LPBF relies in the melting of subsequent layers of metallic powder, whose solidification follows the building direction, the resulting microstructure is typically highly oriented [3]. By observing a $\mathrm{V}$ section, semicircular melt pools can be identified, formed as a consequence of localized melting of the powder bed by means of the laser beam. Along an $\mathrm{H}$ section, instead, melt pools appear elongated as they represent traces of the scanning pattern followed by the laser beam when processing each layer. It is worth mentioning, in fact, that in the present work a chessboard scanning pattern was adopted and the laser wave was continuous. As mentioned above, the solidification of the molten alloy is driven by epitaxial growth that follows the direction of maximum thermal gradient (i.e. the building direction). Therefore, long epitaxial

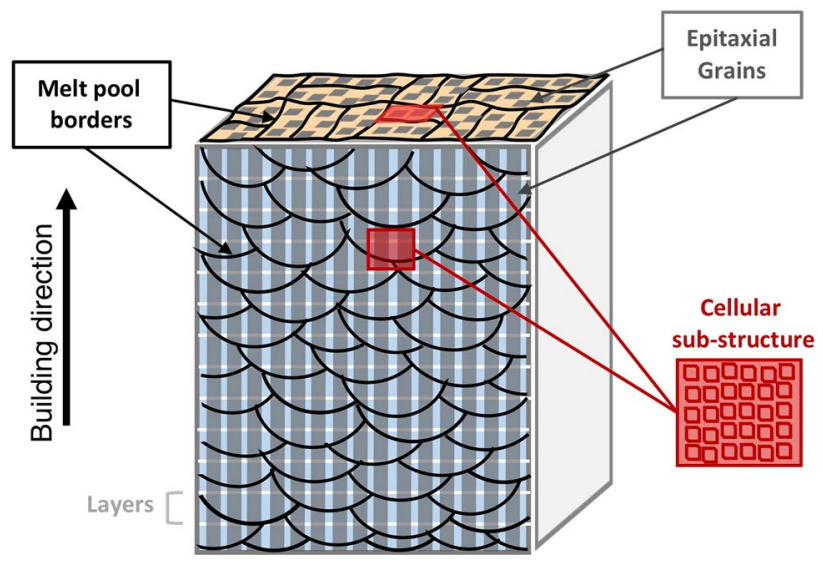

Fig. 2 Schematic representation of the typical LPBF microstructure: evidence of the anisotropy of microstructural features in the direction parallel $(\mathrm{V})$ and perpendicular $(\mathrm{H})$ to the building one 
grains crossing-over layers are formed along the $\mathrm{V}$ direction. The same grains, in an $\mathrm{H}$ section, appear almost equiaxed. Finally, the fine substructure has a cellular morphology in both $\mathrm{V}$ and $\mathrm{H}$ directions. As will be hereafter discussed, results of the microstructural investigations agreed with the schematic representation here examined.

\section{Low-magnification LM}

Low-magnification LM (Fig. 3) enables the general view of the LPBF microstructure, revealing the macro-level microstructural features (i.e. solidified melt pools and epitaxial grains). As a first information, a sound and regular microstructure with no major discontinuities (i.e. defects) was revealed (Fig. 3a, b), proving that processing parameters resulted in high-density samples. Additionally, the anisotropy in the microstructure was revealed as well, demonstrated by the different shape of the solidified melt pools along $\mathrm{V}$ and $\mathrm{H}$ directions. The layered structure formed by subsequent semicircular melt pools is appreciable in section $\mathrm{V}$ (Fig. 3b), while in section $\mathrm{H}$ (Fig. 3a) elongated melt pools forming the chessboard scanning pattern were evidenced.

Accordingly, polarized light microscopy of $\mathrm{V}$ sections (Fig. 3d) highlighted large columnar grains crossing-over layers, due to epitaxy; the same, in $\mathrm{H}$ sections (Fig. 3c), appeared as equiaxed grains.

\section{High-magnification LM}

High-magnification LM (Fig. 4) facilitates the investigation of micro-level microstructural features (i.e. cellular substructure) and the observation of interactions between all microstructural features. For that purpose, the same region was observed using polarized light, bright and dark field. Solidified melt pools due to successive laser scans could be better highlighted by high-magnification bright-field analyses (Fig. 4a, b), whose shape is defined by the melt pool borders (highlighted by white dashed lines in Fig. 4a, b). The fine cellular substructure could be observed by dark filed analyses (Fig. 4c, d) that underlined the presence of an extremely fine structure inside the solidified melt pools. It should be mentioned that, in order to completely resolve the morphology of this substructure, scanning electron microscopy is needed $[14,15]$. However, by comparison with highmagnification polarized LM (Fig. 4e, f) it could be found that differently oriented cellular structures belonged to different grains, in case of both $\mathrm{V}$ and $\mathrm{H}$ sections, proving the highly oriented organization of the LPBF microstructure. This information is usually acquired by more advanced technologies (such as SEM-EBSD). Furthermore, by comparison of bright-field (Fig. 4a, b) and polarized light observations (Fig. 4e, f), it was possible to confirm that epitaxial grains in $\mathrm{V}$ section crossed-over several layers. Additionally, each
Fig. 3 Low-magnification LM micrographs, bright field and polarized light, of: (a) and (c) $\mathrm{H}$ section; (b) and (d) V section

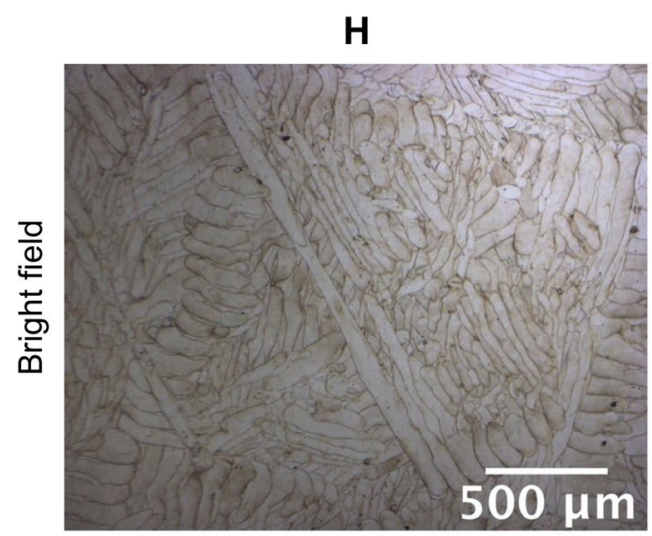

a

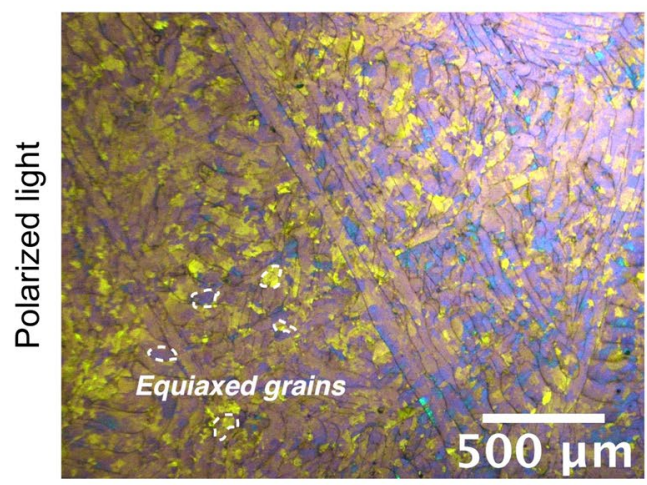

C

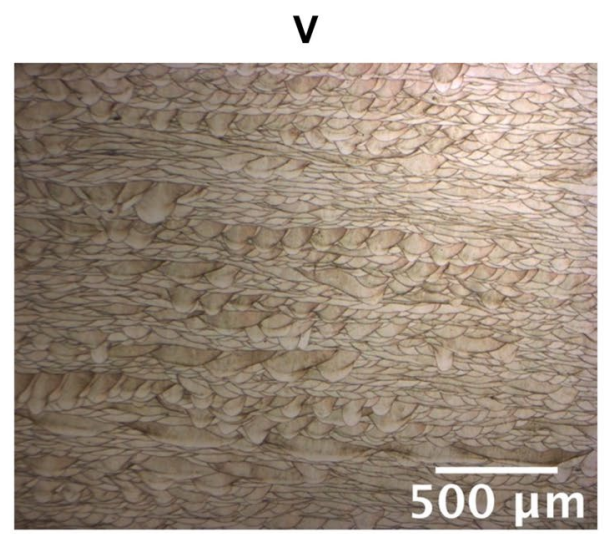

b

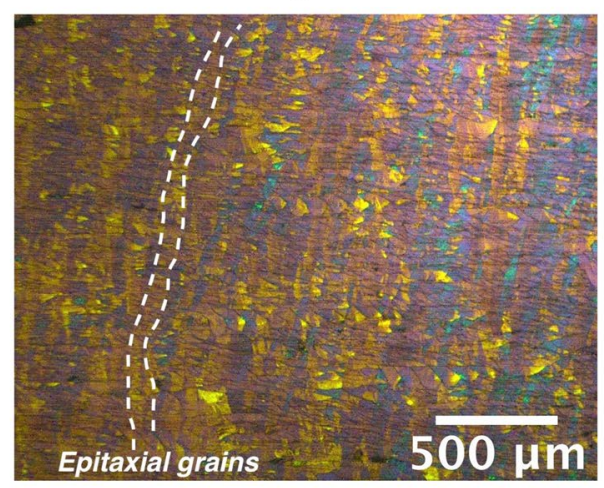

d 
Fig. 4 High-magnification LM micrographs, bright field, dark field and polarized light, of: (a), (c), (e) $\mathrm{H}$ section; (b), (d), (f) $\mathrm{V}$ section.

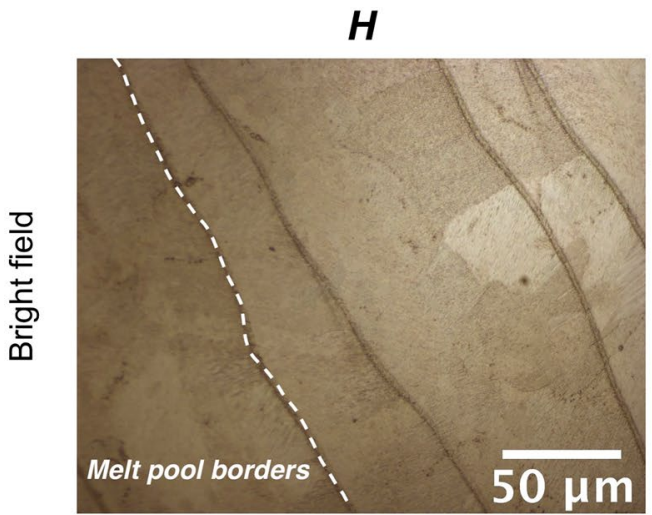

a

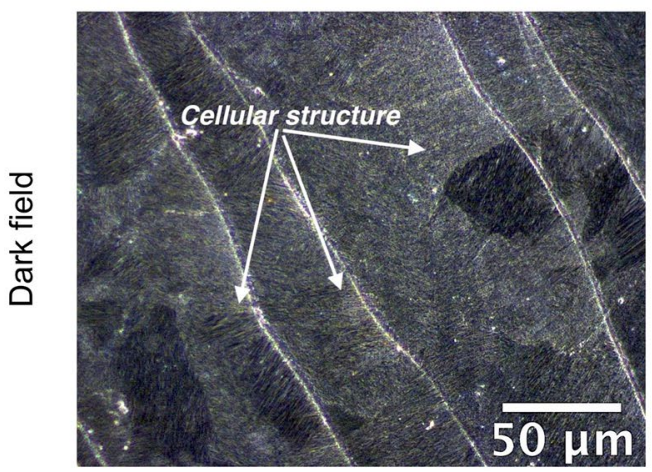

C

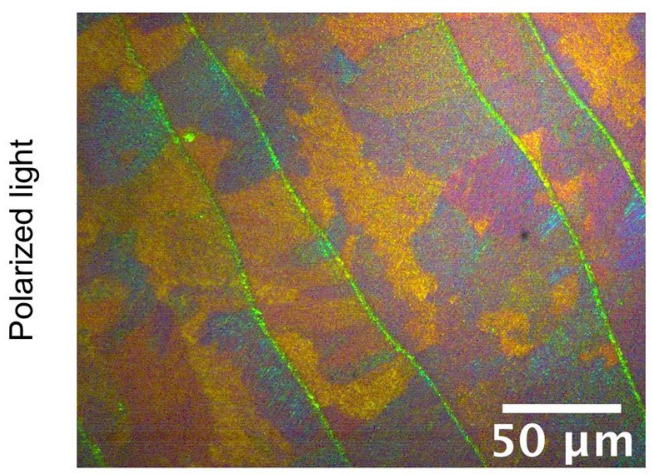

e

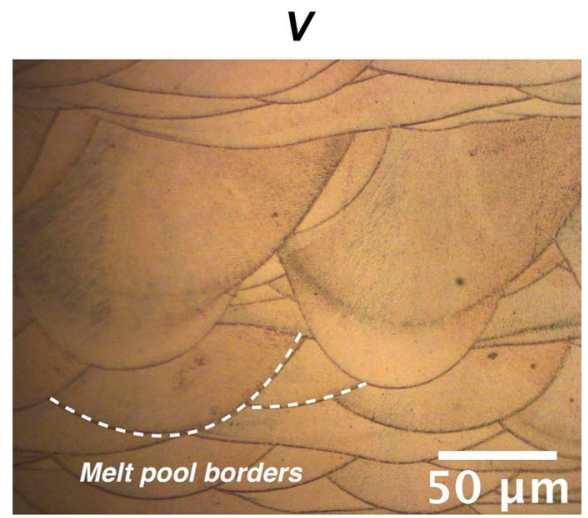

b

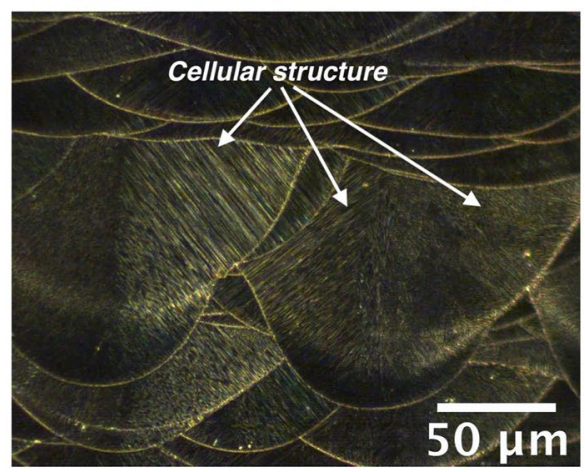

d

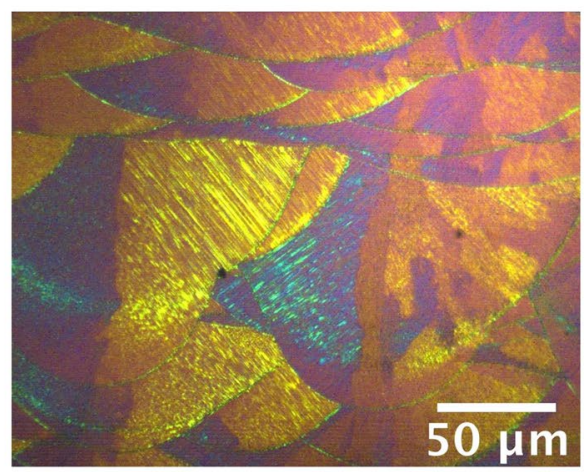

f melt pool was crossed by more than one epitaxial grain, proving that, starting from the border, several grains grew along the single melt pool. The same consideration can be drawn also in case of $\mathrm{H}$ section, where multiple grains were found inside a single melt pool and, in many cases, grains crossed-over adjacent solidified melt pools.

\section{Conclusions}

In the present work, conventional light microscopy (LM) was adopted to characterize and investigate the peculiar microstructure of the Co28Cr6Mo alloy processed by the additive laser-based powder bed fusion (LPBF) process. Two main directions were considered: the vertical one (parallel to the building direction) and the horizontal one (parallel to the building platform). Results showed that main microstructural features typical of LPBF (solidified melt pools, grains and fine substructure) can be simultaneously investigated by LM, with the aid of bright and dark fields and polarized light. As a consequence, conventional light microscopy can be adopted to facilitate and accelerate the preliminary characterization of the peculiar hierarchical and highly oriented microstructure of metal alloys processed by innovative LPBF technology. Basing on a proper optical microscopy, further advanced analyses 
can be more successfully planned and targeted on specific aspects.

Acknowledgements The research activity described in the present work was carried out during the "Mechanics and Advanced Engineering Sciences" PhD course at the University of Bologna. Prof. Lorella Ceschini (University of Bologna), $\mathrm{PhD}$ supervisor, is greatly and kindly acknowledged for her scientific support. The precious contribution of Dr Erica Liverani and Dr Iuri Boromei (University of Bologna) in samples production and analysis is also recognized.

Funding Open access funding provided by Alma Mater Studiorum Università di Bologna within the CRUI-CARE Agreement.

Open Access This article is licensed under a Creative Commons Attribution 4.0 International License, which permits use, sharing, adaptation, distribution and reproduction in any medium or format, as long as you give appropriate credit to the original author(s) and the source, provide a link to the Creative Commons licence, and indicate if changes were made. The images or other third party material in this article are included in the article's Creative Commons licence, unless indicated otherwise in a credit line to the material. If material is not included in the article's Creative Commons licence and your intended use is not permitted by statutory regulation or exceeds the permitted use, you will need to obtain permission directly from the copyright holder. To view a copy of this licence, visit http://creativecommons.org/licenses/by/4.0/.

\section{References}

1. A. Vafadar, F. Guzzomi, A. Rassau, K. Hayward, A. Vafadar, F. Guzzomi, A. Rassau, K. Hayward, Advances in metal additive manufacturing: a review of common processes, industrial applications, and current challenges. Appl. Sci. (2021). https://doi.org/ 10.3390/app11031213

2. S.L. Sing, W.Y. Yeong, S.L. Sing, W.Y. Yeong, Laser powder bed fusion for metal additive manufacturing: perspectives on recent developments. Virtual Phys. Prototyp. 15, 359-370 (2020). https:// doi.org/10.1080/17452759.2020.1779999

3. T. DebRoy, H.L. Wei, J.S. Zuback, T. Mukherjee, J.W. Elmer, J.O. Milewski, A.M. Beese, A. Wilson-Heid, A. De, W. Zhang, T. DebRoy, H.L. Wei, J.S. Zuback, T. Mukherjee, J.W. Elmer, J.O. Milewski, A.M. Beese, A. Wilson-Heid, A. De, W. Zhang, Additive manufacturing of metallic components-process, structure and properties. Prog. Mater. Sci. 92, 112-224 (2018). https://doi. org/10.1016/j.pmatsci.2017.10.001

4. G.M. Karthik, H.S. Kim, G.M. Karthik, H.S. Kim, Heterogeneous aspects of additive manufactured metallic parts: a review. Met. Mater. Int. 27, 1-39 (2021). https://doi.org/10.1007/ s12540-020-00931-2

5. A. Basak, S. Das, A. Basak, S. Das, Epitaxy and microstructure evolution in metal additive manufacturing. Annu. Rev. Mater. Res. 46, 125-149 (2016). https://doi.org/10.1146/annur ev-matsci-070115-031728

6. K.G. Prashanth, J. Eckert, K.G. Prashanth, J. Eckert, Formation of metastable cellular microstructures in selective laser melted alloys. J. Alloys Compd. 707, 27-34 (2017). https://doi.org/10. 1016/j.jallcom.2016.12.209

7. A. Takaichi, T. Suyalatu, N. Nakamoto, N. Joko, Y. Nomura, S. Tsutsumi, H. Migita, S. Doi, A. Kurosu, N. Chiba, Y.
Wakabayashi, T. Igarashi, A. Takaichi, T. Suyalatu, N. Nakamoto, N. Joko, Y. Nomura, S. Tsutsumi, H. Migita, S. Doi, A. Kurosu, N. Chiba, Y. Wakabayashi, T. Igarashi, Hanawa, Microstructures and mechanical properties of Co-29Cr-6Mo alloy fabricated by selective laser melting process for dental applications. J. Mech. Behav. Biomed. Mater. 21, 67-76 (2013). https://doi.org/10. 1016/j.jmbbm.2013.01.021

8. K. Darvish, Z.W. Chen, M.A.L. Phan, T. Pasang, K. Darvish, Z.W. Chen, M.A.L. Phan, T. Pasang, Selective laser melting of Co-29Cr-6Mo alloy with laser power 180-360 W: cellular growth, intercellular spacing and the related thermal condition. Mater. Charact. 135, 183-191 (2018). https://doi.org/10.1016/j.matchar. 2017.11.042

9. Z.W. Chen, M.A.L. Phan, K. Darvish, Z.W. Chen, M.A.L. Phan, K. Darvish, Grain growth during selective laser melting of a CoCr-Mo alloy. J. Mater. Sci. 52, 7415-7427 (2017). https://doi.org/ 10.1007/s10853-017-0975-Z

10. B. Qian, K. Saeidi, L. Kvetková, F. Lofaj, C. Xiao, Z. Shen, B. Qian, K. Saeidi, L. Kvetková, F. Lofaj, C. Xiao, Z. Shen, Defectstolerant $\mathrm{Co}-\mathrm{Cr}-\mathrm{Mo}$ dental alloys prepared by selective laser melting. Dent. Mater. 31, 1435-1444 (2015). https://doi.org/10.1016/j. dental.2015.09.003

11. C. Song, M. Zhang, Y. Yang, D. Wang, Y. Jia-kuo, C. Song, M. Zhang, Y. Yang, D. Wang, Y. Jia-kuo, Morphology and properties of CoCrMo parts fabricated by selective laser melting. Mater. Sci. Eng. A. 713, 206-213 (2018). https://doi.org/10.1016/j.msea. 2017.12.035

12. E. Liverani, A. Fortunato, A. Leardini, C. Belvedere, S. Siegler, L. Ceschini, A. Ascari, E. Liverani, A. Fortunato, A. Leardini, C. Belvedere, S. Siegler, L. Ceschini, A. Ascari, Fabrication of Co-Cr-Mo endoprosthetic ankle devices by means of Selective Laser Melting (SLM). Mater. Des. 106, 60-68 (2016). https://doi. org/10.1016/j.matdes.2016.05.083

13. V. Laghi, M. Palermo, L. Tonelli, G. Gasparini, L. Ceschini, T. Trombetti, V. Laghi, M. Palermo, L. Tonelli, G. Gasparini, L. Ceschini, T. Trombetti, Tensile properties and microstructural features of $304 \mathrm{~L}$ austenitic stainless steel produced by wire-andarc additive manufacturing. Int. J. Adv. Manuf. Technol. (2020). https://doi.org/10.1007/s00170-019-04868-8

14. L. Tonelli, A. Fortunato, L. Ceschini, L. Tonelli, A. Fortunato, L. Ceschini, CoCr alloy processed by Selective Laser Melting (SLM): effect of Laser Energy Density on microstructure, surface morphology, and hardness. J. Manuf. Process. 52, 106-119 (2020). https://doi.org/10.1016/j.jmapro.2020.01.052

15. L. Tonelli, I. Boromei, A. Fortunato, L. Ceschini, L. Tonelli, I. Boromei, A. Fortunato, L. Ceschini, Selective Laser Melting of a CoCrMo alloy for biomedical applications: correlations between microstructure and process parameters. Metall. Ital. 111, 41-47 (2019)

16. D. Klarstrom, P. Crook, J. Wu, Metallography and Microstructures of Cobalt and Cobalt Alloys, in: G.F. Vander Voort (Ed.), Metallography and Microstructures-ASM Handbook, vol. 9, ASM International, 2004: pp. 762-774. https://doi.org/10.31399/asm. hb.v09.a0003771.

Publisher's Note Springer Nature remains neutral with regard to jurisdictional claims in published maps and institutional affiliations. 